\title{
La cooperativa como institución agraria en Cuba: principios normativos que la sostienen
}

\author{
Andy Rojas Jiménez ${ }^{1}$
}

Sumario: Surgimiento del cooperativismo y características. Las cooperativas en Cuba. Principios de las cooperativas en Cuba. Principios normativos de las cooperativas en Cuba. Bibliografía. Legislación.

Resumen: Las Cooperativas de Producción Agropecuarias y las de Créditos y Servicios en Cuba, a pesar de su carácter social y revolucionario, se desvían del real entendimiento del ente cooperativo, según lo entendido como tal históricamente. Fundan su funcionamiento en un conjunto de principios normativos, que ayudan a este alejamiento, y que en la realidad provocan disolución entre lo normado y la práctica, por lo que su modificación se torna urgente.

Palabras claves: cooperativa; principios; producción agropecuaria.

Abstract: The Agricultural Production Co-operatives and Credit and Services in Cuba, despite its social and revolutionary deviate from their real understanding of being co-operative, as historically understood al such. They base their operation on a set of guiding principles that help this deviation and that in reality causes dissolution between the rules and practice, so it becomes an urgent amendment.

Key words: co-operative; principles; agricultural production.

1 Profesor de Derecho en el Centro Universitario Municipal adcrito a la Universidad de Pinar del Río; abogado de Bufetes Colectivos y miembro del Comité Municipal de Atención al Sector Agrario (Municipio Sandino, Provincia Pinar del Río, Cuba). 


\section{Surgimiento del cooperativismo y características}

El ser humano, desde la etapa primitiva, sintió la necesidad de asociarse para lograr nuevas metas, que llenaran o por lo menos que hicieran más fáciles las necesidades y aspiraciones que individualmente eran imposibles de alcanzar ${ }^{2}$. De las maneras de asociación, es la cooperativa la que más larga data posee y sus incipientes expresiones se tuvieron lugar en la comunidad primitiva, a través del trabajo cooperado. Se conoce que antes que los conquistadores españoles y foráneos arribaran a América, las culturas mayas, aztecas e incas, utilizaba métodos cooperados para la realización de actividades agrarias.

En la Edad Media, aún cuando las manifestaciones no fueron de gran trascendencia para el fenómenos cooperativo, si resaltan las congregaciones en determinados pueblos cristianos, el surgimiento de asociaciones cooperadas, en los que primaban sentimientos de solidaridad y mutualidad.

El cooperativismo surge como una necesidad del proletariado sobre la base de la lucha de clases para afrontar las condiciones extremadamente inhumanas del capitalismo premonopolista a mediados del siglo XIX. Su base ideológica parte de los conceptos enunciados por los socialistas utópicos, que los trabajadores podía dirigir la producción dentro de los marcos del mercado 3 .

Las referencias más inmediatas sobre esta institución se ubican durante la Revolución Industrial, cuando la explotación extrema del trabajo se convirtió en fuente de capital para los poseedores de riquezas. Esta situación, la enfrentaron los despojados mediante dos formas asociativas: el sindicalismo y el cooperativismo. El primero en relación mayoritariamente con el salario; el segundo a través de la autoorganización socioempresarial en formas cooperativas.

Las primeras manifestaciones organizacionales cooperativas creadas en el mundo fueron una respuesta de la clase trabajadora a las duras condiciones de la explotación del hombre por el hombre. Las originarias cooperativas del siglo XIX, existieron encaminadas a optimizar las circunstancias de trabajo de los asalariados, a conceder a éstos de formas para la mejora de la atención médica, la edificación de moradas y

2 Vid. Fernández Peiso, Avelino. «El fenómeno cooperativo en Cuba», en formato digital, en CD con materiales sobre Derecho Agrario, Postgrado Nacional celebrado en Las Tunas, del 29 de octubre al 3 de noviembre del 2007.

3 Vid. Rodríguez Membrado, E.: «Apuntes sobre cooperativas de Italia», citado por un Colectivo de AUtores en «Introducción a la Gerencia en Cooperativas Cañeras», p. 13, Ediciones Azucareras, La Habana, 2002. 
la accesibilidad a medios de consumo de mejor calidad. Estas ideas primigenias del cooperativismo, tuvieron gran influencia en la labor educativa y de divulgación de los principios del cooperativismo entre los trabajadores.

Los cimientos teóricos, de la forma cooperativa para oponerse a la explotación del hombre por el hombre, estuvieron en la actividad de Owen y King en Inglaterra, Fourier en Francia, y Raiffeisen en Alemania. Ellos sistematizaron principios y concepciones para brindarles una esperanza a los obreros mediante acciones autoemancipadoras, democráticas, solidarias, educativas y de transformación cultural, económica y social.

En Rochadle, Manchester, Inglaterra, surge en 1844, la primera cooperativa con éxito, formada por obreros textiles, los cuales crean una asociación de consumo para estabilizar los precios y la oferta del mercado en los productos básicos de consumo, a partir de un pequeño aporte de capital de cada uno de los socios. Ellos elaboraron un conjunto de principios sobre los cuales descansa el movimiento cooperativo, los que se han ido perfeccionando según los intereses y condiciones objetivas actuales y son 4 :

1. La incorporación libre y voluntaria, sin discriminación por sexo, raza, religión o posición política.

2. Autonomía e independencia de la organización.

3. Control democrático dado por la participación equitativa en la dirección de la cooperativa por todos los miembros a través de la asamblea de socios.

4. Participación equitativa de los socios para la formación del capital, el cual forma parte de la propiedad colectiva.

5. Educación y formación de los socios para el desarrollo y consolidación de la cooperativa.

6. Cooperación entre las cooperativas para reforzar el movimiento cooperativo.

7. Trabajo por el desarrollo sostenible de la comunidad.

Carlos Marx se refirió, con admiración, a la primera cooperativa creada por obreros industriales, al expresar que «...Resulta una brecha en la sociedad capitalista» ${ }^{5}$, puesto que prueba que los obreros pueden ser sus propios patrones, que era posible organizar y dirigir la produc-

4 Citados por Colectivo de AUtores en «Introducción a la Gerencia en Cooperativas Cañeras», páginas 14 y 15, Ediciones Azucareras, La Habana, 2002.

5 Citado por COLECTIVO DE AUTORES en «Introducción a la Gerencia en Cooperativas Cañeras», p. 13, Ediciones Azucareras, La Habana, 2002. 
ción sin los explotadores burgueses. Ello coincidía con las perspectivas de los fundadores del comunismo científico de una sociedad en la cual no hubiera ni explotados ni explotadores y en la cual las riendas de la producción estuvieran en manos de los trabajadores.

Lenin consideró ${ }^{6}$ que el triunfo del socialismo en Rusia coincidía con el crecimiento, en gran escala, de la cooperación entre toda la población del campo. Su plan cooperativo, el conjunto de sus ideas sobre ese tema, expone la necesidad de llevar al campesino, gradualmente, hacia las cooperativas, en la medida que ello brotara de las necesidades de las masas, con arreglo a su voluntad, como producto de ellas y no creadas desde arriba, de la forma más simple y comprensible para la gente hacia las formas de organización más desarrolladas, movilizando su interés económico y con el apoyo del Estado.

Los notables del marxismo veían que las leyes del liberalismo en la agricultura, provocaban el desarrollo de la capacidad y poder económico de unos latifundios y a la decadencia de otros, a la desaparición de los menos favorecidos por la competitividad, principalmente, a las fincas de los medianos y pequeños productores ${ }^{7}$. Es en este momento en el que era necesaria la intervención estatal, como moderador de la realidad económico-social de la relación entre las formas de cooperativas de forma tal que impidan la desigualdad.

No es hasta la segunda mitad del siglo XIX, en que las organizaciones cooperativas de todo tipo se expanden en las más disímiles esferas de actividad y, sobre todo, en aquellos países donde el nivel de organización, desarrollo social, cultural y de oposición de las masas al capital era mayor. En la actualidad se estima que más de 700 millones de personas en el mundo están afiliadas a cooperativas ${ }^{8}$ en la esfera del consumo, ahorro y crédito, vivienda, pesca, agricultura, servicios y otras actividades.

El Congreso de la Alianza Cooperativa Internacional del año 1995 en Inglaterra definió a las cooperativas como «...una asociación autónoma de personas que se han unido voluntariamente para hacer frente a sus necesidades y aspiraciones económicas, sociales y culturales comunes, por medio de una empresa conjunta y democráticamente controlada» 9 .

6 ĺdem, p. 14.

7 Ibidem.

8 Ibidem, p. 15.

9 Vid. Rodríguez Membrado, E.: «Apuntes sobre cooperativas de Italia», citado por un Colectivo de AUtores en «Introducción a la Gerencia en Cooperativas Cañeras», p. 16, Ediciones Azucareras, La Habana, 2002. 
Este Congreso definió que en la sociedad cooperativa, la propiedad es de todos los socios y sus utilidades son empleadas en su desarrollo, mejoramiento de las condiciones de vida de sus asociados y del entorno comunitario, buscando el beneficio de toda la sociedad. La dirección de la cooperativa se lleva a cabo mediante el principio del control democrático de los socios, los cuales aprueban en Asamblea las medidas y principios que deben seguir en la gestión, eligen a su dirección y ésta tiene la obligación de rendir cuentas, periódicamente, a los miembros.

\section{Las cooperativas en Cuba}

En Cuba, posterior al Triunfo de la Revolución, prevaleció la orientación cooperativa importada de la desaparecida Unión de Repúblicas Socialistas Soviéticas, que las concibió como un modelo de administración de un patrimonio con personalidad jurídica y no como una sociedad de personas al modo cooperativo, trasladando a nuestra realidad un enfoque errado de la forma cooperativa.

En este período revolucionario, el progreso cooperativo recorrió tres momentos ${ }^{10}$. Durante el primero, se expandieron incipientes formas cooperativas de trabajo, como fueron cooperativas cañeras, agrícolas, ganaderas, pesqueras, carboneras, de producción de hilados, de maestros, de servicios y consumo, que fueron las llamadas Tiendas del Pueblo, las que a nuestro juicio no constituyeron verdaderas formas cooperadas, quizás por el concepto que del antiguo campo socialista heredamos.

El segundo momento se inició en los principios de la década del 60, por favorecidos de la Ley de Reforma Agraria; momento en que se crearon las Asociaciones Campesinas, las Organizaciones de Bases de la Asociación Nacional de Agricultores Pequeños (ANAP), las Brigadas de Ayuda Mutua, las Brigadas Federación de Mujeres Cubanas (FMC)-ANAP y se identifica por la creación de las Cooperativas de Créditos y Servicios (CCS); carentes, en ese entonces, de sustento legal.

En los años 70, se da apertura a la formación de las Cooperativas de Producción Agropecuaria (CPA), que adquieren figura legal con la Constitución de 1976, encontrándose su instrumentación en la Ley No. 95 de fecha 2 de noviembre 2002 (que derogó la Ley No. 36 de 1982, antigua Ley de Cooperativas).

10 Vid. Fernández Peiso, Avelino, «El fenómeno cooperativo en Cuba», en formato digital, en CD con materiales sobre Derecho Agrario, Postgrado Nacional celebrado en Las Tunas, del 29 de octubre al 3 de noviembre del 2007. 
El tercer momento, tiene lugar en los años 90, en que los acontecimientos internacionales y la crisis económica estimularon, al Estado cubano, a acudir a la creación de otra forma cooperativa, las Unidades Básicas de Producción Cooperativa (UBPC), forjadas a partir del segmentación de la gran propiedad agrícola estatal, para lo cual se promulga el Decreto Ley 142 de fecha 20 de septiembre de 1993 y las resoluciones reglamentarias de los Ministros de la Agricultura y del Azúcar.

El desplome del campo socialista, la descomposición de la Unión Soviética, como Estado multinacional y gran potencia y la desaparición de las alianzas políticas, económicas y militares que definían el llamado Campo Socialista Europeo, dieron lugar a un desconocido e inconsistente orden internacional, basado en un mercado mundial dominado por relaciones capitalistas de producción, en la concertación entre las grandes potencias y en la hegemonía militar de Estados Unidos ${ }^{11}$.

El impacto de este suceso sobre la Revolución Cubana ha sido particularmente grave para su economía y su seguridad, enfrentándola a la peor crisis de la historia. El sector campesino sufrió una violenta contracción de sus acciones como resultado de una fuerte carestía de energéticos, insumos técnicos, repuestos, alimentos, etc. Esta situación generó una disminución del producto exportable, un descenso de la disponibilidad de alimentos para la población, una fuerte regresión tecnológica, una acelerada descapitalización y una mayor caída de la productividad de los medios y del trabajo.

Estas secuelas se revelaron por igual, aunque en dimensiones diferentes, en las agrupaciones agropecuarias estatales, las cooperativas y los productores individuales. Para desafiar el nuevo escenario de emergencia suscitado por estos eventos se realizaron en el sector numerosos programas de evasiva, tales como:

1. La producción acelerada de alimentos,

2. la readecuación ganadera,

3. el paso a la tracción animal,

4. utilización de otras fuentes energéticas alternativas,

5. la producción de sucedáneos biotecnológicos,

6. la producción de repuestos,

7. la movilización de fuerza de trabajo a la agricultura desde otros sectores, áreas urbanas, estudiantes, etc.

11 Vid. García Alonso, José A.; McComack Bécquer, Maritza de la C. y Balber Pérez, Miguel A. Temas de Derecho Agrario: "Cambios a partir de 1976 en el sector estatal de la agricultura en Cuba. Institucionalización de la propiedad de la tierra en la Constitución de la República». 
Estas políticas perseguían, sin ningún canje orgánico, reunir las capacidades y reservas del país en apoyo a las actividades agropecuarias, para asegurar la sobre vivencia de la población y la recuperación de las exportaciones del país.

El contexto cooperativo cubano congrega a las Cooperativas de Producción Agropecuaria (CPA), a las Cooperativas de Créditos y Servicios (CCS), y a las Unidades Básicas de Producción Cooperativa (UBPC).

La Cooperativa de Producción Agropecuaria (CPA) consiste en un patrimonio con personalidad jurídica, titular de la masa integrada por bienes inmuebles y muebles en condición de propietario, en que se incluyen los frutos de los bienes transmitidos en usufructo, los cuales no forman parte de ese patrimonio; bienes que administra, gestiona y representa para la producción agropecuaria. La cooperativa por su propio derecho, establece relaciones internas con sus socios y externas con los agentes políticos, económicos y sociales.

La Cooperativa de Créditos y Servicios (CCS) también es un patrimonio con personalidad jurídica compuesto por la propiedad de una pequeña masa de bienes inmuebles y muebles y de los frutos de los bienes transmitidos en usufructos - que no forman parte de ese patrimoniotodos los cuales administra, gestiona y representa para el desempeño de su función de intermediación secundaria entre los pequeños agricultores, propietarios o usufructuarios de tierras y otros bienes agropecuarios, y las empresas estatales de comercialización y servicios. La cooperativa por su propio derecho, establece relaciones jurídicas internas con los miembros y externas con los agentes políticos, económicos y sociales.

La Unidad Básica de Producción Cooperativa (UBPC) constituye, asimismo, un patrimonio con personalidad jurídica, compuesto por los bienes agropecuarios y los frutos de la tierra recibida en usufructo, no así esta última; bienes que administra, gestiona y representa para ejecutar producciones agropecuarias. La cooperativa por su propio derecho, establece relaciones internas con sus socios y externas con los agentes políticos, económicos y sociales.

\section{Principios de las cooperativas en Cuba ${ }^{12}$}

1. Constitución, funcionamiento y gestión, previa autorización administrativa.

12 Vid. Según el Profesor Fernández Peiso, Avelino, «El fenómeno cooperativo en Cuba», en formato digital, en CD con materiales sobre Derecho Agrario, Postgrado Nacional celebrado en Las Tunas, del 29 de octubre al 3 de noviembre del 2007. 
2. Adhesión voluntaria sin obligación de aporte patrimonial para su incorporación.

3. Trabajo en común por cuenta de la cooperativa, retribuido con anticipos y utilidades en las CPA y UBPC. Trabajo por cuenta propia en la CCS, por cuyos frutos el agricultor pequeño recibe el valor del importe de sus ventas, denominado beneficios económicos.

4. No responsabilidad patrimonial de los socios por los resultados de la gestión de la cooperativa.

5. Propiedad y/o usufructo de la cooperativa $-\mathrm{y}$ asimismo del cooperativista en las CCS - de la tierra y otros bienes agropecuarios.

6. Democracia interna y autonomía formal.

7. Sujeción al Plan Estatal de la Economía (programas de desarrollo y planes de producción) para la gestión productiva agropecuaria en las CPA, CCS y UBPC y para la compra venta de productos y percepción de servicios para el desarrollo de producciones agropecuarias, en las CCS.

Las cooperativas nacionales son empresas constituidas por un patrimonio dotado de personalidad jurídica, a las que se adscriben voluntariamente trabajadores o titulares de derechos de propiedad o de usufructo sobre la tierra y otros bienes agropecuarios, que tienen como fin la ejecución de producciones agropecuarias o la intermediación en la compraventa de producciones agropecuarias y en la prestación de servicios a sus asociados ${ }^{13}$.

De las CPA pueden ser socios los campesinos aportadores de tierras y bienes agropecuarios, sus familiares y cualesquiera otros campesinos y trabajadores no aportadores, y se les denomina cooperativistas.

A las CCS pueden integrarse los campesinos titulares de derechos de propiedad o usufructos sobre la tierra y demás bienes agropecuarios y sus familiares, las personas naturales no poseedoras de tierras dedicadas a labores de apicultura y otros trabajadores, y se les nombra igualmente cooperativistas.

A la Unidad Básica de Producción Cooperativa se le adscriben los obreros, técnicos y demás trabajadores agropecuarios asalariados del área, sus familiares y otros trabajadores y se les reconoce como cooperativistas o trabajadores o ubepecistas ${ }^{14}$.

13 Ídem.

14 Vid. Sobre la denominación de ubepecistas a los miembros y trabajadores contratados de las UBPC puede verse el artículo de Darío L. Machado Rodríguez, director 
Para la incorporación a cualquier clase de cooperativas la persona natural solo requiere poseer capacidad jurídica civil y laboral, capacidad física para el trabajo, no desempeñar otras funciones laborales, expresar su voluntad de unirse a la cooperativa, obligarse a cumplir las leyes y sus reglamentos y ser aprobados por la correspondiente Asamblea de socios. A los aspirantes a socios no les es exigible ninguna aportación patrimonial para su adscripción. Aceptado el aspirante como socio, ejerce sus derechos y cumple sus deberes conforme lo reglamentado.

Las Asamblea General, como órgano necesario y no permanente que se declara, en las normas, como superior de dirección de la cooperativa y se integra por todos los socios. las CPA y las CCS se eligen a la Junta Directiva y al Presidente por un período de dos años y medio y en las Asambleas de las UBPC se elige a la Junta de Administración y al Administrador por período cinco años; el Presidente o Administrador elegido lo es también de la Junta Directiva o de Administración.

La Asamblea no posee facultades ni funciones directivas, administrativas o ejecutivas, su voluntad se limita a lo interno de la cooperativa, su organización y funcionamiento. Su actuar viene reglado en la Ley y en los Reglamentos generales e internos. El órgano efectivo de dirección y, en consecuencia, de ejecución y administración es la Junta Directiva o de Administración, compuesta por el Presidente o el Administrador y los demás miembros.

La Junta cumple y hace cumplir la Ley, los Reglamentos, las encomiendas de la Asamblea General —acuerdos o mandatos-y las disposiciones legales y reglamentarias que competa al ámbito cooperativo. Posee facultades y responsabilidades de organización, ejecución y control de los procesos de planeamiento, económicos, financieros, producción, servicios y de relaciones externas.

Sus decisiones, emitidas en el ámbito de sus facultades, son de cumplimiento obligatorio y solo revocable por la propia Junta o por la Asamblea General. El Presidente o el Administrador de la cooperativa, ya que es la persona en quién recae su representación legal; constituye el eje central de la cooperativa, se subordina a la Asamblea ante la cual rinde cuentas de su gestión y viene obligado a organizar, dirigir y administrar, asistido por los demás miembros de la Junta Directiva o de Administración, el funcionamiento de la cooperativa. Posee la firma social y representación legal, en consecuencia sus actos obligan a la cooperativa.

del Centro de Estudios sobre América, publicado en la Revista Cuba Socialista No. 1 del 2001, con motivo del debate para el cual lo convocó la revista Cuba Socialista sobre la estructura socialista de la sociedad cubana. 
La tenencia de los bienes cooperativos comprende dos formas de titularidad: la propiedad y el usufructo.

En tanto la economía cooperativa está adscripta a la disciplina del patrimonio, a semejanza de la empresa estatal, ella lleva a considerar que solo los bienes en propiedad integran el patrimonio cooperativo, por lo que de él se excluyen los bienes titulados en usufructo; los frutos resultantes de estos bienes en usufructo si pasan a formar parte del patrimonio cooperativo.

Así el conjunto de bienes que comprende el patrimonio cooperativo está formado por la tierra (excepto las UBPC), los calificados como bienes agropecuarios y otros bienes, (las edificaciones - productivas, sociales, las viviendas - la maquinaria, implementos y equipos agrícolas, de transporte y recreativos adquiridos, construidos o recibidos en propiedad por la cooperativa; los animales, las plantaciones, las producciones agrícolas, forestales u otras y los frutos de los bienes usufructuados) El resto de los bienes (recibidos en usufructo), son también administrados por la cooperativa al efecto de su utilización racional para los fines que en el título se confiere, cuyos frutos sí entran a formar parte del patrimonio cooperativo.

\section{Principios normativos de las cooperativas agrarias en Cuba}

1. Principio de la voluntariedad: Se encuentra plasmado en el artículo 20 de la Constitución cubana, donde expresa que «...los agricultores pequeños tienen el derecho de asociarse, en la forma y con los requisitos que la ley establece...», por lo que se trata de un derecho y no de una obligación. Asimismo el artículo 4 de la Ley No. 95 de la CPA Y CCS establece que «...La Cooperativa de Producción Agropecuaria es una entidad económica que representa una forma avanzada y eficiente de producción socialista con patrimonio y personalidad jurídica propios, constituida con la tierra y otros bienes aportados por los agricultores pequeños, a la cual se integran otras personas, para lograr una producción agropecuaria sostenible...»; y el artículo 5 establece que "...La Cooperativa de Créditos y Servicios es la asociación voluntaria de los agricultores pequeños que tienen la propiedad o el usufructo de sus respectivas tierras y demás medios de producción, así como sobre la producción que obtienen. Es una forma de cooperación agraria mediante la cual se tramita y viabiliza la asistencia técnica, financiera y material que el Estado brinda para aumentar la 
producción de los agricultores pequeños y facilitar su comercialización. Tiene personalidad jurídica propia y responde de sus actos con su patrimonio». No obstante en la propia norma establece en su artículo 3 apartado a que en las cooperativas rige el principio de la «...voluntariedad: la incorporación y permanencia de los miembros de las cooperativas es absolutamente voluntaria».

2. Principio de la ayuda y apoyo del estado socialista: el artículo 18 de la Ley No. 95 dice que «...El Estado y el Gobierno brindan todo el apoyo posible a la constitución, desarrollo y fortalecimiento de las cooperativas... entrega de tierras en usufructo, cuando así sea posible y necesario para la producción de las cooperativas; asistencia técnica para el desarrollo, mediante el suministro de información técnica, acceso a los resultados de las investigaciones y la experimentación, asignación, recalificación y superación postgrado de sus técnicos; prestación de servicios técnicos para la protección de plantas, veterinaria, suelos y agroquímica, certificación de semillas y otros relacionados con la producción agropecuaria; facilitar y colaborar con la introducción de la ciencia y la técnica que sean accesibles a la cooperativa; dotarlas de un marco jurídico específico; asignación de recursos e insumos para la producción y obras sociales; establecimiento de precios justos y estables para sus producciones; otorgamiento de créditos agropecuarios; ayuda económica, de conformidad con las regulaciones establecidas, y otras...».

3. Principio del desarrollo gradual del movimiento cooperativo: se basa en las CCS, las cuales son una muestra palpable de este desarrollo escalonado, manteniendo la propiedad de la tierra y demás medios de producción, se preparan para el avance hacia formas superiores. En el artículo 3 apartado b, de la Ley 95, hace referencia al principio de Cooperación y ayuda mutua, refiriéndose a que «...todos los miembros trabajan y aúnan sus esfuerzos para el uso racional de los suelos y bienes agropecuarios, propiedad o en usufructo de las cooperativas o de los cooperativistas»; y en el propio artículo apartado g, se refiere al bienestar de los cooperativistas y sus familiares al señalar que «...las cooperativas trabajan para lograr la satisfacción racional de las necesidades materiales, sociales, educativas, culturales y espirituales de sus miembros y familiares...». En este mismo sentido, el propio artículo pero su apartado h, se refiere a la colaboración entre cooperativas, expresando que 
«...las cooperativas se prestan colaboración entre sí mediante la compraventa de productos para el autoabastecimiento, pies de cría, semillas, prestación de servicios para la producción, intercambio de experiencias, y otras actividades lícitas sin ánimo de lucro».

4. Principio de la transformación económica y el progreso social: Ello está en consonancia con los fines de las cooperativas en nuestro país, expresándose en el artículo 8 de la citada Ley 95 que las CPA tienen los siguientes fines:

a) Desarrollar con eficiencia económica la producción agropecuaria sostenible, en atención a los intereses de la economía nacional, de la comunidad y de la propia cooperativa;

b) utilizar racionalmente los suelos agrícolas, propiedad o en usufructo de la cooperativa y los demás bienes agropecuarios y recursos productivos con que cuentan;

c) incrementar sostenidamente la cantidad y calidad de las producciones directivas y propiciar su rápida comercialización, y

d) desarrollar otras producciones agropecuarias y forestales y prestar servicios agropecuarios que hayan sido autorizados en su objeto social.

Por su parte los fines expresados en el artículo 9 para las CCS son los siguientes:

a) Planificar, contratar, comprar, vender y utilizar en forma organizada y racional los recursos y servicios necesarios para sus miembros y la cooperativa, en razón de la producción agropecuaria;

b) gestionar, tramitar y colaborar en el control, la utilización y recuperación de los créditos bancarios necesarios para sus miembros y la propia cooperativa, destinados a la producción agropecuaria;

c) planificar y comercializar las producciones directivas de los miembros y de la cooperativa;

d) comercializar otras producciones y servicios autorizados en su objeto social, y

e) adquirir, arrendar y explotar en forma colectiva los equipos agrícolas y de transporte y construir las instalaciones necesarias para mejorar la eficiencia en la producción y comercialización agropecuaria, autorizadas en su objeto social.

Ello acentuado por la regulación expresa en el artículo 3 relacionado con los principios cooperativos ya que en su apar- 
tado c establece la contribución al desarrollo de la economía nacional, cuando refiere que «...todos los planes y programas de las cooperativas están dirigidos y tienen como objetivo fundamental trabajar por el desarrollo económico y social sostenible de la nación».

5. Principio de la atención a las condiciones concretas de cada país: este principio se refleja en toda la legislación cubana sobre la cooperación agrícola, donde cada detalle es en definitiva un reflejo de ello.

6. Principio de la democracia cooperativista: se manifiesta desde el mismo acto de constitución de la cooperativa, decidido en la asamblea que a tal efecto se convoca, el artículo 11 de la Ley 95, establece que «...Los agricultores pequeños tienen derecho a asociarse entre sí en Cooperativas de Producción Agropecuaria, unificar sus tierras y demás bienes agropecuarios de los que son propietarios y expresar su voluntad en la asamblea convocada al efecto, y mediante solicitud formal de constitución a los organismos competentes»; por el mismo estilo el artículo 13 del propio cuerpo normativo establece que «...Los agricultores pequeños propietarios o usufructuarios de tierras, tienen derecho a asociarse en Cooperativas de Créditos y Servicios, expresando su voluntad en asamblea convocada al efecto y mediante solicitud formal de constitución a los organismos competentes». En este sentido los artículos 24 al 30 establecen en sentido general que «...La Asamblea General es el órgano superior de dirección de las Cooperativas de Producción Agropecuaria y las de Créditos y Servicios, se integra por todos los miembros, quienes eligen de su seno mediante el voto secreto y directo al Presidente y demás miembros de la Junta Directiva. La Asamblea se considera válida para esta elección cuando están presentes las dos terceras partes de sus miembros... La Junta Directiva es el órgano de dirección de la cooperativa,... se subordina a la Asamblea General y le rinde cuenta periódicamente de sus actos y decisiones. El Presidente de la Asamblea General, que lo es también de la Junta Directiva, asegura y responde por el cumplimiento de los acuerdos y decisiones de ambos órganos, ostenta la representación legal de la cooperativa y rinde cuenta periódicamente de su gestión ante la Junta Directiva y la Asamblea General. Cuando el Presidente $u$ otro miembro de la Junta Directiva demuestre incapacidad para el cargo, incurra en acciones delictivas en el ejercicio del mismo o en otras conductas que lo hagan desmerecer 
del buen concepto público, puede ser revocado antes del cumplimiento del término de su mandato, por la Asamblea General, la que elige al sustituto».

En este sentido al artículo 3 de la Ley 95, referido a sus principios expresa en el apartado e, relacionado con la decisión colectiva al expresar que «...todos los actos que rigen la vida económica y social de las cooperativas se analizan y deciden en forma democrática por la Asamblea General y la Junta Directiva, en que la minoría acata y se subordina a lo aprobado por la mayoría». Relacionado con el tema encontramos el principio regulado en el apartado d de la propia norma y artículo al señalar la disciplina cooperativista cuando declara que «...todos sus miembros conocen, cumplen y acatan conscientemente, las disposiciones de esta Ley, sus reglamentos, los acuerdos de la Asamblea General y las demás leyes y regulaciones que son de aplicación en las cooperativas».

7. Principio de la unión de los intereses personales con los colectivos en la cooperativa: este principio se expresa en la forma de retribución del trabajo del cooperativista, el cual participa en el recibo de los anticipos y la distribución de las utilidades en la medida del trabajo aportado, por lo que en mayor proporción recibe beneficios la cooperativa y es mayor su aporte social.

8. Territorialidad: referido a la constitución de estos entes agrarios en los territorios donde están enclavadas las tierras de los agricultores pequeños, al decir en el artículo 3 apartado $f$, de la Ley 95 que «...los agricultores pequeños se integran y pertenecen a la cooperativa del territorio en que están enclavadas sus tierras, con el fin de facilitar la mejor y más económica gestión de la cooperativa con relación a sus miembros».

9. Solidaridad humana: referido a la influencia de la existencia del ente agrario para sus miembros y para la comunidad expresándose en la ayuda que puedan brindar y al desarrollo justo de su economía a través de las ventas a precios mejorados para las comunidades donde estén enclavadas. Ello se deduce de la observación del apartado i artículo 3 del propio cuerpo legal al expresar que «...practican la solidaridad humana con sus miembros, trabajadores y demás personas que habiten en las comunidades donde estás enclavadas».

10. Interés social: expresado en la permisibilidad de sus acciones al expresar en el apartado j del propio artículo que «...todos sus actos y acciones tienen como fin el interés social». 
En resumen, esta concepción heredada por Cuba del cooperativismo, ha provocado que realmente la institución en nuestro país, no tenga la connotación necesaria, ni juegue el papel que debiera tener en la realidad cubana. Las políticas de protección del Estado revolucionario para con el sector agrario, ha provocado que el campesino cubano se vea favorecido y protegido, por lo que no siempre siente la necesidad que le viene impuesta por la forma organizacional a la que pertenece. En Cuba, aun cuando las únicas manifestaciones de cooperativismo existentes son las del sector agrario, para nada homologamos nuestra forma de cooperativismo, con la idea originaria del fenómeno, porque no surgen las cooperativas en el territorio nacional como consecuencia de la explotación del hombre por el hombre. Solo véase que las CCS, CPA, y UBPC, surgen en 1993 y 2002, y la Ley anterior a ellas es de 1982, cuando ya en nuestro país se había transcurrido varios años de políticas socialistas.

Si observamos bien, las manifestaciones cooperadas en Cuba encuentran en su constitución una metamorfosis de la cooperativa pura, ya que no nacen como consecuencia de elementos generados por el capitalismo; ni las condiciones de su surgimiento tienen algo que ver con nuestra realidad. En nuestro país, tanto las CPA como las CCS, surgen en virtud del Sistema Normativo sin permiso previo, o Sistema de Concesión, que es aquel mediante el cual el Estado declara que reconoce como persona jurídica a aquellos entes que se constituyan conforme al contenido indicado y a las condiciones impuestas por la ley. El Estado comprueba si dichas condiciones han sido cumplidas por el ente que se le presenta y en caso afirmativo, la constatación oficial de las observancias prescritas y el consiguiente orden de registración y publicidad, son los que le confieren personalidad jurídica al ente, la ley no es la fuente de dicha constitución ${ }^{15}$. Pero la realidad es que si analizamos la historia del surgimiento de nuestras cooperativas agrarias, fue el estado quien, en su misión de unificar al sector agrario cubano, para que estuviera en mejores condiciones de enfrentar la cruda realidad mercantil interna y externa, se tomó la tarea de organizarlos y no surgieron por la voluntad brotada espontáneamente de los campesinos.

Ello, unido a otros elementos ha provocado que las cooperativas en nuestro país, presenten una situación atípica, expresada en la falta de autonomía en la toma de decisiones directivas; problemas de financiamiento; falta de mercado para comercializar los productos; falta de sentido personal sobre lo que entraña la cooperativa; monopolio esta-

15 Vid. Colectivo de autores. Derecho Civil. Parte General, Edición Computarizada, Departamento de Derecho Civil y de Familia, Facultad de Derecho, Universidad de La Habana, 2000, p. 158. 
tal sobre la vida de la cooperativa que limita su actuación; falta de asesoramiento jurídico a la entidad; lo que ha provocado un alejamiento mayor de las CPA y CCS del cooperativismo.

Mucho queda por hacer en Cuba, en relación al ente agrario como manifestación cooperativa. Iniciando ello por la Ley, la que debe modificarse a los efectos de dar mayor autonomía la forma cooperada. Confiamos en su pronta modificación, y en que unidos los cubanos, lograremos formas de cooperativización agraria a la altura del nuevo siglo.

\section{Bibliografía}

1. Colectivos de autores. Derecho Civil. Parte General, Edición Computarizada, Departamento de Derecho Civil y de Familia, Facultad de Derecho, Universidad de La Habana, 2000.

2. Fernández Peiso, Avelino. El fenómeno cooperativo en Cuba, en formato digital, en CD con materiales sobre Derecho Agrario, Postgrado Nacional celebrado en Las Tunas, del 29 de octubre al 3 de noviembre del 2007.

3. García Alonso, José A.; Mccomack Bécquer, Maritza de la C. y Balber Pérez, Miguel A. Temas de Derecho Agrario, "Cambios a partir de 1976 en el sector estatal de la agricultura en Cuba. Institucionalización de la propiedad de la tierra en la Constitución de la República».

4. Rodríguez Membrado, E. "Apuntes sobre cooperativas de Italia», citado por un Colectivo de Autores en «Introducción a la Gerencia en Cooperativas Cañeras», Ediciones Azucareras, La Habana, 2002.

\section{Legislación}

1. Acuerdo del Comité Ejecutivo del Consejo de Ministros, de fecha 17 de mayo del 2005, que aprueba los Reglamentos Generales de las Cooperativas de Producción Agropecuaria y de Créditos y Servicios, en ColeCTIVO DE AUTORES, Temas de Derecho Agrario Cubano, Selección Legislativa de Derecho Agrario Cubano, Editorial Félix Varela, La Habana, 2007.

2. Constitución de la República de Cuba, texto reformado en 2002, en Gaceta Oficial de la República de Cuba, Extraordinaria. Año Cl, No.3, 31 de enero de 2003.

3. Decreto Ley No. 142, sobre las Unidades Básicas de Producción Cooperativas, de fecha 20 de septiembre de 1993, en ColeCtIVo DE AUtores, Temas de Derecho Agrario Cubano, Selección Legislativa de Derecho Agrario Cubano, Editorial Félix Varela, La Habana, 2007.

4. Ley No. 95, de Cooperativas de Producción Agropecuaria y de Créditos y Servicios, de fecha 2 de noviembre 2002, en COLECTIVO DE AUTORES, Temas de Derecho Agrario Cubano, Selección Legislativa de Derecho Agrario Cubano, Editorial Félix Varela, La Habana, 2007. 